\title{
Analysis and Prospect of Treatment Measures for Black - odorous Water Sediment in China
}

\author{
Zhongwei Zhang ${ }^{1,2}$, Yubo Cui ${ }^{1,2, *}$, Junwen $\mathrm{Ma}^{1}$, Xuejun Zou ${ }^{1,2}$, and Zhaobo Chen ${ }^{1,2}$ \\ ${ }^{1}$ Key Laboratory of Biotechnology and Bioresources Utilization, Ministry of Education, Dalian Minzu University, Dalian 116600, China \\ ${ }^{2}$ College of Environment and Resources, Dalian Minzu University,Dalian 116600 , China
}

\begin{abstract}
In recent years, black-odorous water bodies have been seriously polluted, and the release of endogenous pollution from sediments has once again caused harm to water bodies. How to deal with the black-odorous water sediment has become a widespread concern in the process of building ecological civilization. This article analyzes the sources, hazards, types, and treatment technologies of sediment pollution, including dredging and dredging technology, dredging and post-treatment technology, sediment cover technology, chemical agent dosing technology, microbial remediation technology, and aeration recovery oxygen technology, submerged phytoremediation technology and so on . The article gives suggestions and measures for the treatment of sediment from the aspects of external pollution control, implementation of measures according to local conditions, and development of new technologies.rocesses.
\end{abstract}

\section{Introduction}

Since the reform and opening up, China's urbanization and industrialization road construction has developed rapidly. However, due to relatively backward environmental governance measures and insufficient water pollution control capabilities, large areas of urban and rural water bodies have been polluted, and rivers and lakes have been seriously polluted, causing eutrophication of water bodies and forming blackodorous water. With the increasing number of blackodorous water, people feel the inconvenience of life and harsh environment, the State Council promulgated the "Water Pollution Prevention Action Plan" regulations in April 16, 2015, so that the black-odor water more and more people's attention. Due to the continuous influx of external pollution, pollutants have been deposited in the sediment of the water body for a long time, and the problem of treating the black-odorous water sediment is an important part to solve the internal pollution.

\section{Sediment pollution}

\subsection{Sources of sediment pollution}

When externally polluted organic matter and animal and plant humus enter the water body, the dissolved oxygen in the water is quickly consumed when the aerobic bacteria treat the organic matter. When the dissolved oxygen in the water cannot reach equilibrium again, a large amount of organic matter is further decomposed by the action of anaerobic bacteria. generating $\mathrm{H}_{2} \mathrm{~S}$, mercaptans, sulfides and other odorous substances, the sediment of $\mathrm{Fe}^{2+}, \mathrm{Mn}^{2+}$ other metal ions and anaerobic generated $\mathrm{S}^{2-}$ reaction $\mathrm{FeS}$ and $\mathrm{MnS}$ and other black materials.These blackened substances and a large amount of organic and refractory inorganic substances have been precipitated and enriched in the sediment for a long time, which has caused the sediment to be contaminated.

\subsection{Harm of sediment pollution}

The random discharge of urban, rural, and industrial wastewater can easily cause heavy metals to be present in the sediment, causing excessive levels of heavy metals around the water body, and causing damage to the ecology of the water body. When the sediment is contaminated, the contaminated sediment will continuously release pollutants such as nitrogen, phosphorus and heavy metals into the overlying water, which is likely to cause secondary pollution of the water body. Sediment pollution causes severe hypoxia in the lower layer of the water body, and aquatic plants and animals cannot survive. The gas produced by denitrification and methanation in the sediment will drive the sediment to float and float in the overlying water, forming a foul odor and affecting the senses.

\subsection{Types of sediment pollution}

\subsubsection{Heavy metals}

The heavy metals in the polluted water mainly come from the random discharge, staggered discharge of industrial wastewater, and environmental protection

\footnotetext{
*orresponding author: $\underline{\mathrm{cyb} @ \text { dlnu.edu.cn }}$
} 
measures. After heavy metals enter the water body, they are deposited in the sediment through the action of adsorption, complexation, redox, colloidal precipitation, etc., causing serious damage to the photosynthesis and respiration of aquatic plants, and enrichment through the food chain, ultimately endangering human health.

\subsubsection{Nutrients}

A large amount of urban and rural domestic sewage is discharged into the water body in different ways, which causes the nitrogen, phosphorus and other nutrients in the water body to exceed the standard, and the water body is eutrophic. These nutrients accumulate and precipitate into the mud after long-term accumulation. When nitrogen, phosphorus and other nutrients are released from the sediment to the water body, algae will multiply in large quantities and blooms will occur.

\subsubsection{Refractory organic matter}

Hard-to-degrade organic substances refer to organic chemicals that are difficult to biodegrade under natural conditions. Synthetic detergents, organochlorine pesticides, polychlorinated biphenyls and other compounds, fats and oils are more difficult to biodegrade in water. Because they are difficult to degrade, they are usually deposited in large quantities in the sediment.

\section{Sediment treatment technology}

\subsection{Sediment Dredging and Dredging Technology}

Dredging and dredging technologies generally include drainage dredging, underwater dredging and environmental protection dredging. Drainage and dredging is only applicable to rivers with small flow, no flood prevention and drainage, and will increase the cost of temporary cofferdam construction. Underwater dredging is easy to cause secondary pollution by agitating the water body to turn the sludge into floating sludge. When the impurities in the sediment are complex, it will cause a burden on the operation of the dredging equipment and the pipeline system. Environmental protection dredging takes the environmental protection as the primary purpose for dredging. Prospects Very broad.

\subsection{Sediment dredging and post-treatment technology}

\subsubsection{Sediment drying technology}

Commonly used sediment drying and dehydration technologies include vacuum pre-compression technology, geotechnical bag technology, centrifugal dewatering technology, and plate and frame filtration technology. The vacuum preloading technology has a long vacuum running time, and the removal effect of high-thickness mud water content is not obvious. The sludge dehydration rate is affected by the material of the closed membrane and the actual pressure difference. The geotechnical tube bag technology has a sludge treatment capacity which is affected by the pipe belt and the pressure and cannot be processed in a large amount in a short time. Centrifugal dewatering technology is not recommended for its incomplete solid-liquid separation of sludge and small processing capacity. The plate and frame filter press method is simple to operate and has obvious separation effect. It is also the most common sludge post-treatment technology.

\subsubsection{Sediment solidification technology membrane treatment technology}

Sediment solidification technology forms a new type of environmentally friendly foundation material by mixing the sediment and the curing agent. Traditional curing agents are cement, fly ash and gypsum. In recent years, some scholars have researched the use of mixed curing agents to further improve the solidification strength of the sediment. P.L. Shi et al. [1] used $8 \%$ cement and $2 \%$ gypsum as a silt curing agent to carry out ecological transformation on the current bank. $7 \mathrm{~d}$ increased to $10.87 \mathrm{Mpa}$ and meets the requirements of slope compressive strength. However, the curing strength cannot be improved over time. After the traditional cured brick is formed, the curing strength needs to be further strengthened under the fire sintering process. However, Y. Chen et al. [2] developed a solidification and nonfiring conversion, which replaced the traditional calcination process. The moisture content of the sludge was $25 \%$, the amount of cement was $8 \%$, and the amount of liquid soil curing agent was $0.02 \%$. After 28 days of curing, the average compressive strength of the five test blocks was $10.89 \mathrm{MPa}$, the minimum strength of a single block was $9.03 \mathrm{MPa}$, and the strength level was MU10.0. The solidified non-fired bricks have reduced part of the sintering process, which greatly reduces the economic burden of sludge post-treatment, but the natural curing time is too long. It is still questionable whether the cured non-fired brick can be used repeatedly without causing pollution. Sediment solidification technology has broad prospects and high environmental benefits, but the composite curing agent still needs to be developed and optimized.

\subsection{Sediment cover technology}

The surface of the sediment is covered with one or more layers of non-hazardous repair materials, and the physical separation of the sediment from the overlying water prevents the pollutants in the sediment from spreading into the overlying water again. Some scholars have shown that $\mathrm{CaO}_{2}$ coverage and dosing will significantly improve $\mathrm{pH}$ and $\mathrm{DO}$ in the overlying water body, and the removal effect of TP is better than $\mathrm{CaO}_{2}$ injection dosing [3]. In earlier studies, zeolite can effectively inhibit the release of nitrogen and phosphorus in sediments and is widely used in sediment cover 
materials [4]. H.J. Zhang et al. [5] through six groups of experiments: zeolite coverage $+\mathrm{Ca}\left(\mathrm{NO}_{3}\right)_{2}$ dissolution injection, $\mathrm{Ca}\left(\mathrm{NO}_{3}\right)_{2}$ dissolution injection, zeolite coverage $+\mathrm{CaO}_{2}$ dissolution injection, $\mathrm{CaO}_{2}$ dissolution injection, zeolite coverage, and blank six experiments After the 15th sampling, the experimental group showed that the experimental group containing zeolite cover was better than the single chemical injection experimental group in treating the sediment pollutants. When the treatment time is prolonged, the coverage effect of a single zeolite will be weaker than the chemical injection treatment and gradually deteriorate. In actual application, the sediment cover technology is more difficult. The application of cover material may raise the river bed, and the cover material is affected by water conditions such as water flow velocity and pressure.

\subsection{Chemical agent dosing technology}

Chemical oxidant is one of the most commonly used methods to treat the sediment. It can release a large amount of oxygen by oxidative decomposition with organic pollutants in the sediment or react with water to improve the anaerobic environment of the sediment and purify the water. The four commonly used chemical oxidants are calcium oxide, calcium nitrate, hydrogen peroxide, and calcium hydroxide, and the repair effect is single and does not last. D.F. Liu [6], who also treated by mixing calcium nitrate and channel black-odor denitrifying bacteria sediment, sediment results show that the amount of addition of treating agent administered $2000 \mathrm{mg} / \mathrm{L}$, the sediment AVS removal rate was $73.3 \%$. W.P. Li et al. [7] used low-dose calcium nitrate combined with low-oxygen aeration to repair the sediment. The research found that the average removal rates of $\mathrm{NH}_{3}-\mathrm{N}$ and AVS in the sediment reached $76.8 \%$ and $97.4 \%$, respectively . In the $4 \mathrm{~d}$ before the reaction, the $\mathrm{NH}_{3}-\mathrm{N}$ content in the sediment and overlying water increased due to the influence of calcium nitrate. When the treatment time continued to increase, calcium nitrate had a stimulating effect on the activity of denitrifying bacteria in the sediment, and the $\mathrm{NH}_{3}-\mathrm{N}$ content in the sediment and overlying water was greatly reduced. In addition to chemical oxidants, agents such as aluminum, iron, and calcium salts can also inhibit the release of sediment contaminants [8]. The method of applying chemical agents focuses on the selection of the agent types and the control of the amount of dosing, as well as the specificity of the sludge pollutant components. It is also necessary to pay attention to the problem of the destruction of water ecosystems by the addition of chemical agents.

\subsection{Microbial repair technology}

Microbial reproduction ability is strong, can naturally purify water bodies and degrade most organic pollutants in sediment. W. Cheng [9] conducted experiments on the treatment of sewage sludge with added microorganisms and blank control group under reoxygenation aeration. Within 30 days of the reaction, the thickness of the sediment decreased from $10 \mathrm{~cm}$ to $2 \mathrm{~cm}$, and the COD removal rate of the sediment reached $69 \%$. The thickness of the sediment was increased by microbial strains and then decreased in 1 to 3 days. After 30 days, the thickness of the sediment was stable at $2 \mathrm{~cm}$. Photosynthetic bacteria and denitrifying bacteria have better remediation effects in the sediment, but they are both limited by ambient temperature and photosynthetic bacteria are more sensitive to $\mathrm{pH}[10]$. Biostimulants can stimulate the activity of aerobic flora in the sediment and promote oxidative decomposition. Some scholars believe that the number of anaerobic flora and its enzyme activity are the basis and necessary conditions for the black odor of the sediment [11], but there are few studies in this area. Whether it is a microbial species or a biostimulant, it needs to be analyzed on a case-by-case basis. It cannot be used blindly to cause problems such as breaking the ecological balance of the original water body, alien species invasion, and secondary pollution.

\subsection{Sediment aeration and reoxygenation technology}

Sediment aeration and reoxygenation can increase the dissolved oxygen content in the water body, stimulate the metabolic activity of aerobic microorganisms, and promote the oxidative decomposition ability of sediments. Relevant scholars found that under the conditions of indoor simulation experiments, the closer the aeration head is from the mud-water surface to $0 \mathrm{~cm}$, the more obvious the oxidation-reduction potential of the sediment increases [12]. At this stage, the aeration and reoxygenation of the sediment is more used as the prestage or auxiliary stage of ecological treatment to improve the aerobic environment of the sediment. For example, L.M. Xue et al. [13] used artificial microporous aeration in the early stage, and the removal rates of chemical oxygen demand (COD), total nitrogen (TN), and total phosphorus (TP) in water bodies reached $79.23 \%, 90.89 \%$, and $63.83 \%$, respectively. The DO concentration in the water was maintained at $2.7 \sim 3.2 \mathrm{mg}$ / L. Sediment aeration is an efficient reoxygenation method, which provides early protection for subsequent biological and ecological treatment, but the aeration amount, aeration point, and dissolved oxygen content cannot be controlled within a stable range; aeration equipment consumes large power and costs High, unable to achieve precise aeration .

\subsection{Submerged phytoremediation technology}

Submerged plants absorb organic pollutants from the sediment as plant growth nutrients, which are important measures in the ecological restoration of plants. At present, the main research directions are the tolerance of submerged plants and the development of root systems.Some researchers used Sagiaaria pygmaea Miq to conduct experiments on the tolerance of heavy polluted sediment and the removal of major pollutants in South China. After 180 days, the number of plants expanded by 20 times. In the experimental results, the 
root and canopy length of Sagiaaria pygmaea Miq is much longer than other submerged plants, and the removal rates of ferrous and acidic volatile sulfur in the sediment are $92.6 \%$ and $96.3 \%$, respectively [14]. Phytoremediation technology is less expensive and can build a healthy ecosystem. However, submerged plants generally have problems such as seasonality, north-south adaptability, etc. At the beginning of planting, they may be affected by harsh environmental conditions and may not survive. Aquatic plants need to be harvested annually, resulting in additional human and financial resources. Breeding new species may make up for some shortcomings. study.

\section{Conclusions and expectation}

The treatment of black and odorous body sediments is a long-term and complicated project. In recent years, more and more researches have been conducted on the treatment of sediments. The treatment method has been continuously innovated. The combination of theory and practice has continued to strengthen the proportion of environmental protection. In the future, we should focus on the following aspects:

(1) promulgate relevant laws and regulations and strictly control the entry of external pollution into water bodies. Reduce the mixed flow of rainwater and sewage in urban and rural areas, and eliminate the leakage of industrial wastewater. In particular, do a good job in garbage classification, improve municipal waste and sewage treatment measures, and curb the generation of black and odorous water bodies from the source .

(2) according to local conditions, a strategy for the treatment of sediments should be implemented. The composition of pollutants in different sediments in different regions will be different, and the "one river, one policy" plan will be achieved.

(3) develop new technologies, optimize and apply multiple technologies. In the actual application, the best technology combination is selected to reduce construction costs and achieve both landscape and ecological benefits.

\section{Acknowledgements}

The research was financed by the Science and Technology Innovation Foundation of Dalian, China (2018J12SN080) and Natural Science Foundation (National Innovation Joint Fund) of Liaoning, China.

\section{References}

1. P.L. Shi, Resources Economization \& Environment Protection, Application of Sludge Dehydration and Solidification Technology in the Treatment of Black and Odorous Water Bodies, 06, 106-107 (2019)

2. Y. Chen, M. Huang, Y.J. Zhang, et al. Fujian Building Materials, Experimental Study on Preparation of Silt-cured Non-fired Bricks Using River Silt, 06, 6-7 (2019)
3. Y. Xu, D.P. Li, F.E. Han, et al. Environ. Sci. Inhibition of Endogenous Phosphorus Release from Sediments of Black and Odorous River by Different Dosing Methods of $\mathrm{CaO}_{2}, \mathbf{3 8}, 2836-2842$ (2017)

4. Q.M. Liu, L. Cheng, B.X. Shen, et al. Journal of Jimei University(Natural Science), Zeolite Barrier Control Factors Sediment Nitrogen and Phosphorus Release Reservoirs, 05, 18-21 (2010)

5. H.J. Zhang, S. Li, L. Zhang, et al. Environ. Eng. Analysis on Black-odor Sediment Pollutant Inhibition Effect of Different In-situ Treatment Methods, 37, 37-41 (2019)

6. D.F. Liu, X.Y. Wang, W.B. Wang, et al. South-toNorth Water Transfers Water Sci. Technol. Experimental Study of Black-odor Sediment Control Repair Tianjin Situ Biochemical Methods, 17, 70-75 (2019)

7. W.P. Li, S.K. Zhang, X.G. Li, Research of Environmental Sciences, Study on the Restoration of Black-odorous Sediment by Low-dosages Calcium Nitrate Combined with Hypoxic Aeration, 04, 1-12 (2020)

8. L.X. Huang, Y. Shi, T.T. Huang, et al. Shandong Chem. Ind. Discussion on the Treatment Methods of Black Muddy River Sediment, 48, 256-258 (2019)

9. W. Cheng, Environ. Sustainable Dev. Study on Sediment Treatment of Black Odor Water Based on Microbial Rehabilitation Technology, 44, 151-153 (2019)

10. M.Q. Niu, G.Y. Su, Y.B. Qiao, et al. Guangzhou Chem. Ind. Microbial Remediation of Sediment in Black and Stink Water, 47, 125-126 (2019)

11. H.Q. Sun, S.X. Sheng, Z. Yang, et al. Environmental Science Survey, Analysis of Blackodor Factors of Lake Sediment and Elimination Strategies of Key Factor, 38, 12-20 (2019)

12. S.L. Liao, Y.X. Pu, L.X. Xu, et al. Guangzhou Chem. Ind. Effect of Aeration on River Sediment and Overlying Water, 46, 60-62 (2019)

13. L.M. Xue, Urban Roads Bridges \& Flood Control, Research on Ecological Purification and Restoration of Urban Landscape Rivers, 08, 149151 (2019)

14. S.Q. Gao, Z.Y. Chen, F.M. Li, et al. Acta Sci. Circumstantiae, Tolerance of Sagittaria Pygmaea Miq to Heavily Polluted Sediments and Its Removal of Major Pollutants, 39, 2182-2189 (2019) 